Pacific Journal of Mathematic 


\section{SOLUTION OF THE MIDDLE COEFFICIENT PROBLEM FOR CERTAIN CLASSES OF $C$-POLYNOMIALS}

\section{ZALMAN RUBINSTEIN}

A well-known conjecture states that for polynomials having all their zeros on the unit circle $C$ half the maximum modulus on $C$ bounds the modulus of all the coefficients. This has been established in all cases except for the middle coefficient of even degree polynomials greater than four. In this note this conjecture is verified for all even degree polynomials having simple zeros in a set of arcs dividing the circle into equal parts and related classes of polynomials. The local extremal polynomials are identified.

1. Introduction. Throughout this note polynomials whose zeros all lie on the unit circumference $C=\{\boldsymbol{z}|| \boldsymbol{z} \mid=1\}$ will be considered and refered to as $C$-polynomials. If $P$ is a polynomial $M(P)=$ $\operatorname{Max}_{z \in C}|P(z)|$. Also $P^{*}(z)=z^{n} \overline{P(1 / \bar{z})}$, where $n$ is the degree of $P$.

The following conjecture due to P. Erdös was stated in [3], and in corrected form in [4].

Conjecture 1. Let

$$
P(z)=a_{n} z^{n}+\cdots+a_{1} z+a_{0}
$$

be a $C$-polynomial. Then $\left|a_{i}\right| \leqq M(P) / 2$ for $i=0,1, \cdots, n$. This conjecture was established in [5] and [6] for all cases except $n=2 k$ and $i=k$. In [6] another conjecture was raised in this connection.

Conjecture 2. If the zeros of $P(z)$ in (1) all lie on the exterior of $C$ then $\left|a_{i}\right| \leqq M(P) / 2$ for $n / 2 \leqq i \leqq n$. For comparison we add

Conjecture 3. If the degree of $P(z)$ in (1) is even $n=2 k$ then $\left|a_{k}\right| \leqq M(P) / 2$.

The special significance of Conjecture 3 is that it actually is equivalent to Conjectures 1 and 2 but its statement is the most economical. This is summarized in

Lemma 1. Conjecture 3 implies Conjectures 1 and 2.

Proof. (a) If $P(z)$ is a $C$-polynomial given by (1) then $P^{2}(z)=$ $c_{2 n} z^{n}+\cdots+c_{n} z^{n}+\cdots+c_{0}$ is an even degree $C$-polynomial and $c_{n}=$ 
$u\left(\left|a_{0}\right|^{2}+\cdots+\left|a_{n}\right|^{2}\right)$ where $|u|=1$ and $a_{k}=u \bar{a}_{n-k}$. If Conjecture 3 is true

$$
2\left|c_{n}\right| \leqq M\left(P^{2}\right)=M^{2}(P)
$$

In particular

$$
2\left|a_{i}\right|^{2}=\left|a_{i}\right|^{2}+\left|a_{n-i}\right|^{2} \leqq \frac{M^{2}(P)}{2}
$$

if $i \neq n / 2$, so that $\left|a_{i}\right| \leqq M(P) / 2$.

(b) Let $Q(z)=b_{n} z^{n}+\cdots+b_{0}$ be a polynomial of degree $n$ whose zeros all lie on the closed exterior of $C$. The polynomials $Q(z)+e^{i \theta} z^{m} Q^{*}(z)$ are easily seen to be $C$-polynomials for any nonnegative integer $m$ and any real $\theta$. Indeed $\left|Q_{n}(z)\right| \leqq\left|Q^{*}(z)\right|$ for $|z| \geqq 1$ and $|Q(z)| \geqq\left|Q^{*}(z)\right|$ for $|z| \leqq 1$. Thus we construct $C$-polynomials of degree $(m+n)$ whose $k$ th coefficient is $b_{k}+e^{i \theta} b_{n-k+m}$. Since $\left|Q^{*}(z)\right| \leqq|Q(z)|$ on $|z|=1$, for a suitable choice of $\theta$ we have

$$
\left|b_{k}\right|+\left|b_{j}\right| \leqq \frac{1}{2}(2 M(Q))=M(Q)
$$

for $j=n-k, n-k+1, \cdots, n$. If $k \geqq n / 2$ we can also choose $j=k$ to obtain $\left|b_{k}\right| \leqq M(Q) / 2$. This concludes the proof of the lemma.

We may also remark that the above mentioned conjectures have corresponding counterparts for trigonometric polynomials $T_{n}(\theta)$ of degree $n$ with only real zeros. It is easily seen that Conjecture 1 can be stated as an integral inequality

$$
\left|\int_{0}^{2 \pi} T_{n}(\theta) d \theta\right| \leqq \pi M\left(T_{n}\right)
$$

where $M\left(T_{n}(\theta)\right)=\operatorname{Max}_{\theta \in R}\left|T_{n}(\theta)\right|$.

For these polynomials the inequality

$$
\int_{0}^{2 \pi}\left|T_{n}(\theta)\right| d \theta \leqq 4 M\left(T_{n}\right)
$$

was conjectured by P. Erdös and established in [6].

In this note we shall verify Conjecture 3 for several classes of $C$-polynomials including the family of $C$-polynomials whose zeros lie on fixed disjoint open arcs of length $2 \pi / n$ on the unit circle one zero on each arc. Although the proof of the main theorem will focus on this family other classes are mentioned following the proof.

2. The main results. Let $n=2 k$. Denote by $S_{0}, \cdots, S_{2 k-1}$ the open disjoint arcs on the unit circle of length $\phi=\pi / k$ whose endpoint are the $n$th roots of unity. Also let $S_{0}^{\varepsilon}, \cdots, S_{2 k-1}^{\varepsilon}$ for $\varepsilon>0$ sufficient- 
ly small denote the closed ares obtained from $S_{0}, \cdots, S_{2 k-1}$ by deleting two symmetric subarcs of length $\varepsilon$ on each end. $\pi_{n}$ and $\pi_{n, \varepsilon}$ shall denote the class of $C$-polynomials of degree $n$ whose zeros $z_{j} \in S_{j}$ and $z_{j} \in S_{j}^{\epsilon}$ respectively $(j=0,1, \cdots, n-1)$. Furthermore if

$$
Q(z)=q_{2 k} z^{2 k}+\cdots+q_{k} z^{k}+\cdots+q_{0}
$$

then

$$
M(Q)=\operatorname{Max}_{z \in C}|Q(z)| \text { and } L(Q)=\left|a_{k}\right| / M(Q) .
$$

We shall consider the values

$$
\alpha=\sup _{Q \in \pi_{n}} L(Q)
$$

and

$$
\alpha_{\varepsilon}=\max _{Q \in \pi_{n} \varepsilon} L(Q) .
$$

It is clear that monic $C$-polynomials $P_{0}$ and $P_{\varepsilon}$ assuming the extremal values $\alpha$ and $\alpha_{\varepsilon}$ exist. Moreover they can be chosen such that $P_{0} \in \bar{\pi}_{n}$ and $P_{\varepsilon} \in \pi_{n, \varepsilon}$ where the closure is the uniform closure on compact subsets in the plane.

We shall write

$$
P_{\varepsilon}(z)=a_{2 k, \varepsilon} z^{2 k}+\cdots+a_{k, \varepsilon} z^{k}+\cdots+a_{0, \varepsilon} .
$$

The zeros of $P_{\varepsilon}(z)$ all lie in $\bigcup_{j=0}^{2 k-1} S_{j}^{\varepsilon}$, they are simple and there is exactly one zero in each of the arcs $S_{j}^{\varepsilon}$.

In the proof of the main theorem we shall need two auxiliary results.

THEOREM A. [1] Let $\Gamma$ be a circle in the complex plane and let $\gamma_{i}(i=1,2, \cdots, n)$ be disjoint open arcs on $\Gamma$. Let $z_{0} \in \Gamma-\bigcup_{i=1}^{n} \gamma_{i}$. Then for any $w_{0} \neq 0$, the set of polynomials $P$ of degree $n$ having exactly one zero in each of the arcs $\gamma_{i}$ and satisfying $P\left(z_{0}\right)=w_{0}$ is convex.

The next result applies to all regular functions.

LEMmA 2. [2] Let $w(z)$ be regular in the unit disk, with $w(0)=0$. Then if $|w|$ attains its maximum value on the circle $|z|=r$ at a point $\zeta$, we can write

$$
\zeta w^{\prime}(\zeta)=k w(\zeta)
$$

where $k=k(|\zeta|, w)$ is real and $k \geqq 1$.

Now we state the main theorem. 
THEOREM. Let $Q(z)=q_{2 k} z^{2 k}+\cdots+q_{k} z^{k}+\cdots+q_{0}$ be a C-polynomial of degree $2 k$.

(a) If $Q \in \pi_{2 k, s}$ then

$$
\frac{\left|q_{k}\right|}{M(Q)} \leqq \frac{1}{1+\sec \varepsilon}
$$

and all extremal polynomials are of the same form $c P^{*}\left(z e^{i r}\right)$ where

$$
P^{*}(z)=z^{2 k}+2 \cos \varepsilon z^{k}+1 .
$$

(b) For all $Q \in \bar{\pi}_{2 k},\left|q_{k}\right| / M(Q) \leqq 1 / 2$.

Proof. Let $P_{\varepsilon}(z)$ be an extremal polynomial in the class $\pi_{n, s}$, given by (5). For $\phi=\pi / k$ and fixed $\varepsilon>0$ let $R_{j}(z)=P_{\varepsilon}\left(z e^{i j \phi}\right), j=$ $0,1, \cdots, 2 k-1$. Then $R_{j}(z) \in \pi_{n, s}$ and hence by Theorem $\mathrm{A}$ the polynomials

$$
R(z)=\sum_{j=0}^{2 k-1} \alpha_{j} \frac{R_{j}(z)}{R_{j}(1)}
$$

are also in $\pi_{n, s}$ for $\alpha_{j} \geqq 0, \sum_{j=0}^{2 k-1} \alpha_{j}=1$. Since $R(z)$ is a solution of the extremal problem (4) we have

$$
L\left(\sum_{j=0}^{2 k-1} \alpha_{j} \frac{R_{j}(z)}{R_{j}(1)}\right) \leqq L\left(R_{0}\right) .
$$

(8) can be written as

$$
M\left(R_{0}\right)\left|\sum_{j=0}^{2 k-1} \frac{\alpha_{j} e^{i \pi j}}{R_{j}(1)}\right| \leqq M\left(\sum_{j=0}^{2 k-1} \alpha_{j} \frac{R_{j}(z)}{R_{j}(1)}\right) .
$$

Since $R_{0}(z)=P_{\varepsilon}(z)=a_{2 k, \varepsilon} z^{2 k}+\cdots+a_{k, \varepsilon} z^{k}+\cdots a_{0, \varepsilon}$ is a $C$-polynomial $a_{2 k-m, \varepsilon}=u \bar{a}_{m, \varepsilon}$ for $m=0,1, \cdots, 2 k$ and for some $u=e^{i \theta}$. Therefore $R_{0}(z) z^{-k} e^{(-i \theta / 2)}$ is real on $C$. In particular the numbers $r_{j}=$ $R_{j}(1) e^{-\pi j i} e^{-(i \theta / 2)}$ are real for $j=0,1, \cdots, 2 k-1$. Moreover since $R_{0}$ has $2 k$ simple zeros on the intervals $S_{j}^{\varepsilon}$ the numbers $r_{j}$ have constant sign. Thus (9) can be written in the form

$$
M\left(R_{0}\right) \leqq M\left(\sum_{j=0}^{2 k-1}(-1)^{j} b_{j} R_{j}\right)
$$

for $b_{j} \geqq 0, \sum_{j=0}^{2 k-1} b_{j}=1$.

Observing that $M\left(R_{j}\right)=M\left(R_{0}\right)$ and letting all the even $b_{j}$ (or the odd $b_{j}$ ) equal to zero we obtain

$$
M\left(R_{0}\right) \leqq M\left(\sum_{l=0}^{k-1} b_{2 l} R_{2 l}\right) \leqq \sum_{l=0}^{k-1} b_{2 l} M\left(R_{2 l}\right)=M\left(R_{0}\right) .
$$

(10) implies the existence of a point $z_{1}$ on $C$ such that $R_{2 l}\left(z_{1}\right)=$ 
$M\left(R_{0}\right) e^{i \alpha}$ for $l=0, \cdots, k-1$. The polynomial $R_{0}$ assumes maximum modulus at $k$ symmetrically situated points on $C$. Moreover it assumes there the same value. Therefore setting $M_{0}=M\left(R_{0}\right)$ we have

$$
R_{0}(z)-M_{0} e^{i \alpha}=\left(z^{k}-\gamma\right) q(z)
$$

where $q(z)$ is a polynomial of degree $k$ and $\gamma \in C$. Let $w_{l}, l=$ $0, \cdots, k-1$ denote the kth roots of $\gamma$. We have by (11)

$$
q\left(w_{l}\right)=\frac{R_{0}\left(w_{l}\right)}{k w_{l}^{k-1}}=\frac{1}{k \gamma} w_{l} R_{0}^{\prime}\left(w_{l}\right) .
$$

By Lemma 2 applied to the analytic functions $z R_{0}(z)$ there exists a nonnegative constant $c$ independent of $w_{l}$ such that

$$
w_{l} R_{0}^{\prime}\left(w_{l}\right)=c R_{0}\left(w_{l}\right)
$$

for $l=0,1, \cdots, k-1$. Combining (12) and (13) we have

$$
q\left(w_{l}\right)=c_{1} R_{0}\left(w_{l}\right)
$$

where $c_{1}=c / k \gamma$. Hence by (14)

$$
q(z)-c_{1} R_{0}(z)=\left(z^{k}-\gamma\right) s(z)
$$

where $s(z)$ is a polynomial of degree $k$.

By (11) and (15) $\left(z^{k}-\gamma\right)$ divides the polynomials $\left(c_{1} R_{0}-M_{0} c_{1} e^{i \alpha}\right)$ and $\left(q-c_{1} R_{0}\right)$ and therefore divides the polynomial $\left(q-M_{0} c_{1} e^{i \alpha}\right)$. Since $q$ is of degree $k$

$$
q(z)=c_{2} z^{k}+c_{3}
$$

for some constants $c_{2}$ and $c_{3}$.

Finally by (11)

$$
R_{0}(z)=a_{2 k, \varepsilon} z^{2 k}+a_{k, \varepsilon} z^{k}+a_{0, \varepsilon} .
$$

It is now easy to evaluate $L\left(R_{0}\right)$. For a second degree polynomial $t(w)=(w-\zeta)(w-\bar{\zeta})$ the maximum of $|t(w)|$ is attained at the points $w=1$ or $w=-1$ or both. Therefore

$$
L\left(R_{0}\right)=\frac{|\operatorname{Re} \zeta|}{1+|\operatorname{Re} \zeta|} .
$$

$x /(1+x)$ is increasing for $x>0$. This establishes (6) for the class $\pi_{2 k, s}$ for all sufficiently small $\varepsilon$ (actually one may restrict $\varepsilon$ to $0<$ $\varepsilon<\pi / 2 k)$.

The preceeding argument also easily implies (7) for the extremals of $\pi_{n, \varepsilon}$ up to the transformations indicated. Every polynomial in $\pi_{n}$ is a uniform limit of polynomials in $\pi_{n, \varepsilon}$ as $\varepsilon \rightarrow 0$. This completes 
the proof.

We conclude with a few corollaries.

COROLlaRY 1. If $T_{n}(\theta)$ is a trigonometric polynomial of degree $n$ whose $2 n$ zeros all lie ion $2 n$ disjoint adjacent closed intervals which can be mapped by a linear transformation onto $2 n$ symmetric equal arcs on $C$, one zero in each interval, then $T_{n}(\theta)$ satisfies the sharp inequality (2).

COROLlaRY 2. Conjecture 3 remains true if the zeros of the C-polynomials of degree $2 k$ considered lie pairwise on disjoint arcs of length $\pi / k$ provided no two such pairs lie on disjoint arcs $\bmod (\pi / k)$.

This follows from the fact that only rotations by multiples of $\pi / k$ were used in the proof of the theorem and the condition above allows the application of Theorem A. As an example consider a $C$ polynomial of degree $2 k$ whose zeros have arguments $\left(\pi / 2 k_{j} \pm \varepsilon_{j}\right)$, $j=1,3, \cdots, 2 k-1$, where $\varepsilon_{j}\left(0<\varepsilon_{j}<\pi / 2 k\right)$ is a monotonic sequence of positive numbers.

We finally remark that the method outlined here can be applied to other extremal problems such as the case where the coefficient of the polynomial is arbitrary.

Added in Proof. Conjecture 3 in form (2) has been recently established by G. K. Kristiansen in the paper "Some inequalities for algebraic and trigonometric polynomials" J. London Math. Soc. (2), 20 (1979), 300-314. The estimate of the main theorem of this paper is independent of the above mentioned result.

\section{REFERENCES}

1. H. J. Fell, On the zeros of convex combinations of polynomials, Pacific. J. Math., (to appear).

2. I. S. Jack, Functions stralike and convex of order $\alpha$, J. London Math. Soc., (2) (1971), 469-474.

3. W. K. Hayman, Research problems in function theory, Athlone Press, London, 1967.

4. —- Research Problems in Function Theory, Symposium on Complex Analysis Canterbury, (1973), 143-154.

5. P. J. O'hara and R. S. Rodriguez, Some properties of self-inversive polynomials, Proc. Amer. Math. Soc., 44 (1974), 331-335.

6. E. B. Saff and T. Sheil-Small, Coefficient and integral mean estimates for algebraic and trigonometric polynomials with restricted zeros, J. London Math. Soc., (2) 9 (1974), 16-22. 
Received June 5, 1979.

The University of Michigan

ANN ARBor, MI 48109

AND

UNIVERSITY OF HAIFA

HAIFA, ISRAEL 



\section{PACIFIC JOURNAL OF MATHEMATICS}

\section{EDITORS}

DONALD BABBITT (Managing Editor)

University of California

Los Angeles, CA 90024

HUGo RossI

University of Utah

Salt Lake City, UT 84112

C. C. MOORE and ANDREW OGG

University of California

Berkeley, CA 94720
J. DugundJI

Department of Mathematics

University of Southern California

Los Angeles, CA 90007

R. FinN and J. Milgram

Stanford University

Stanford, CA 94305

ASSOCIATE EDITORS
E. F. BECKENBACH
B. H. NeUmanN
F. WOLF
K. YoSHIDA

\section{SUPPORTING INSTITUTIONS}

UNIVERSITY OF BRITISH COLUMBIA

CALIFORNIA INSTITUTE OF TECHNOLOGY

UNIVERSITY OF CALIFORNIA

MONTANA STATE UNIVERSITY

UNIVERSITY OF NEVADA, RENO

NEW MEXICO STATE UNIVERSITY

OREGON STATE UNIVERSITY

UNIVERSITY OF OREGON
UNIVERSITY OF SOUTHERN CALIFORNIA

STANFORD UNIVERSITY

UNIVERSITY OF HAWAII

UNIVERSITY OF TOKYO

UNIVERSITY OF UTAH

WASHINGTON STATE UNIVERSITY

UNIVERSITY OF WASHINGTON

The Supporting Institutions listed above contribute to the cost of publication of this Journal, but they are not owners or publishers and have no responsibility for its content or policies.

Mathematical papers intended for publication in the Pacific Journal of Mathematics should be in typed form or offset-reproduced, (not dittoed), double spaced with large margins. Please do not use built up fractions in the text of the manuscript. However, you may use them in the displayed equations. Underline Greek letters in red, German in green, and script in blue. The first paragraph or two must be capable of being used separately as a synopsis of the entire paper. Please propose a heading for the odd numbered pages of less than 35 characters. Manuscripts, in triplicate, may be sent to any one of the editors. Please classify according to the scheme of Math. Reviews, Index to Vol. 39. Supply name and address of author to whom proofs should be sent. All other communications should be addressed to the managing editor, or Elaine Barth, University of California, Los Angeles, California, 90024.

50 reprints to each author are provided free for each article, only if page charges have been substantially paid. Additional copies may be obtained at cost in multiples of 50 .

The Pacific Journal of Mathematics is issued monthly as of January 1966. Regular subscription rate: $\$ 84.00$ a year (6 Vols., 12 issues). Special rato: $\$ 42.00$ a year to individual members of supporting institutions.

Subscriptions, orders for numbers issued in the last three calendar years, and changes of address shoud be sent to Pacific Journal of Mathematics, P.O. Box 969, Carmel Valley, CA 93924, U.S.A Old back numbers obtainable from Kraus Periodicals Co., Route 100, Millwood, NY 10546.

PUBLISHED BY PACIFIC JOURNAL OF MATHEMATICS, A NON-PROFIT CORPORATION

Printed at Kokusai Bunken Insatsusha (International Academic Printing Co., Ltd.). 8-8, 3-chome, Takadanobaba, Shinjuku-ku, Tokyo 160, Japan.

Copyright (C) 1980 by Pacific Jounal of Mathematics Manufactured and first issued in Japan 


\section{Pacific Journal of Mathematics \\ Vol. 89, No. $2 \quad$ June, 1980}

Frank Hayne Beatrous, Jr. and R. Michael Range, On holomorphic

approximation in weakly pseudoconvex domains................. 249

Lawrence Victor Berman, Quadratic forms and power series fields ...... 257

John Bligh Conway and Wacław Szymański, Singly generated antisymmetric operator algebras ....................... 269

Patrick C. Endicott and J. Wolfgang Smith, A homology spectral sequence for submersions . . . .................................

Sushil Jajodia, Homotopy classification of lens spaces for one-relator groups with torsion ................................ 301

Herbert Meyer Kamowitz, Compact endomorphisms of Banach

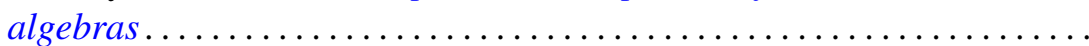

Keith Milo Kendig, Moiré phenomena in algebraic geometry: polynomial

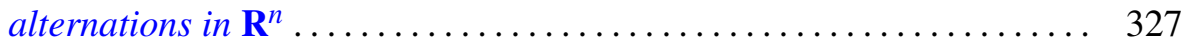

Cecelia Laurie, Invariant subspace lattices and compact operators....... 351

Ronald Leslie Lipsman, Restrictions of principal series to a real form . . . . . 367

Douglas C. McMahon and Louis Jack Nachman, An intrinsic

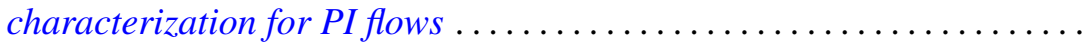

Norman R. Reilly, Modular sublattices of the lattice of varieties of inverse semigroups .................................... 405

Jeffrey Arthur Rosoff, Effective divisor classes and blowings-up of $\mathbf{P}^{2}$ 419

Zalman Rubinstein, Solution of the middle coefficient problem for certain

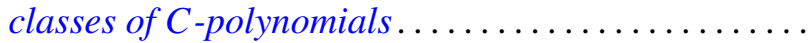

Alladi Sitaram, An analogue of the Wiener-Tauberian theorem for spherical transforms on semisimple Lie groups ................

Hal Leslie Smith, A note on disconjugacy for second order systems ...

J. Wolfgang Smith, Fiber homology and orientability of maps ...

Audrey Anne Terras, Integral formulas and integral tests for series of positive matrices. 